\title{
Quercetin suppresses NF-кB and MCP-1 expression in a high glucose-induced human mesangial cell proliferation model
}

\author{
PIN CHEN $^{1 *}$, QIYANG SHI ${ }^{2 *}$, XIANGJIN XU ${ }^{1}$, YANQIAO WANG $^{1}$, WENYU CHEN $^{1}$ and HUILING WANG ${ }^{1}$ \\ ${ }^{1}$ Fuzhou General Hospital of Nanjing Military Command, Fuzhou, Fujian 350025; ${ }^{2}$ The Second Affiliated \\ Hospital of Fujian Medical University, Quanzhou, Fujian 362000, P.R. China
}

Received December 29, 2011; Accepted February 16, 2012

DOI: $10.3892 / \mathrm{ijmm} .2012 .955$

\begin{abstract}
Diabetic nephropathy (DN), which is characterized by mesangial cell proliferation, is a common complication observed in diabetic patients. The protective effects of quercetin for DN have been reported; however, the mechanism has yet to be determined. We aimed to identify the underlying mechanism for quercetin protection against DN. High glucose (HG)-induced human mesangial cell (HMC) proliferation, a feature of the early stages of diabetic nephropathy, was employed as an in vitro model. Cells were grown in normal glucose $(5.6 \mathrm{mM})$, high glucose $(30 \mathrm{mM})$ or high glucose with various concentrations of quercetin. Cell proliferation, cell cycle progression, and expression of $\mathrm{NF}-\kappa \mathrm{B}$ and MCP-1 were examined by MTT assay, DNA staining, immunocytochemistry and western blot analysis, respectively. HMCs cultured in high glucose had signficantly greater proliferation, accumulation in the G1 phase, upregulated NF- $\mathrm{B}$ and MCP-1 expression. Quercetin treatment reversed the effects of high glucose in a dose-dependent manner. Cotreatment of quercetin with pyrrolidine dithiocarbamate (PDTC), an inhibitor of NF- $\kappa \mathrm{B}$ activation, suggest that the effects of quercetin are partially mediated by NF- $\kappa \mathrm{B}$ signaling. Quercetin partially suppresses the effects of high glucose in HMC cultures, which are mediated at least in part through the suppression of $N F-\kappa B$.
\end{abstract}

Correspondence to: Dr Xiangjin Xu, Fuzhou General Hospital of Nanjing Military Command, Fuzhou, Fujian 350025, P.R. China

E-mail: xjinxu163@163.com

*Contributed equally

Abbreviations: ANOVA, analysis of variance; DN, diabetic nephropathy; HG, high glucose; HMC, human mesangial cell; NG, normal glucose, NF- $\mathrm{kB}$, nuclear factor- $\mathrm{kB}$; PKC, protein kinase $\mathrm{C}$; PDTC, pyrrolidine dithiocarbamate; ROS, reactive oxygen species; QU, quercetin; SDs, standard deviations; STZ, streptozotocin; MTT, tetrazolium blue

Key words: diabetic nephropathy, human mesangial cells, nuclear factor- $\kappa \mathrm{B}$, quercetin, chemoattractant protein-1

\section{Introduction}

Diabetes mellitus is widely considered to be an inflammatory disease (1), and diabetic neuropathy (DN) is a commonly observed serious complication. Human mesangial cell (HMC) proliferation is a histological feature of $\mathrm{DN}$; it is also observed in renal diseases, causing loss of renal function and subsequent failure (2). However, the precise cellular mechanisms governing HMC hyperproliferation remain unclear although diverse stimuli, including growth factors, inflammatory mediators, and metabolic abnormalities such as hyperglycermia, are known to induce HMC proliferation (3).

Quercetin is a flavonoid that naturally occurs in plants in various glycosidic forms and has potentially beneficial effects in numerous medical conditions (4). Quercetin interacts with phosphoinositide 3-kinases (5), a family of enzymes that regulate cell growth, proliferation, and differentiation; they are also involved in the pathogenesis of diabetes mellitus $(6,7)$. Studies in animal and/or cell models have also indicated that quercetin possesses anti-inflammatory properties and quenches free radicals $(8,9)$. Protective effects of quercetin in diabetes mellitus and DN have also been reported in rat models (10-12). In addition, the protective effects of quercetin have been observed in a streptozotocin (STZ)-induced model of diabetes mellitus (11-14). Furthermore, Kim et al (15) reported that dietary quercetin attenuated fasting and postprandial hyperglycemia. In portal hypertensive rats, quercetin blocked $N F-\kappa B$ signaling, thereby reducing the production of compounds that mediate the pathogenesis of portal hypertensive gastropathy (16). These studies indicate a theoretical basis for the clinical use of quercetin to prevent and treat DN; however, the mechanisms mediating its protective effects have yet to be determined.

The objective of this study was to identify the underlying mechanism for quercetin protection against $\mathrm{DN}$, the most commonly observed serious complication of diabetes mellitus with a feature of hyperproliferation of mesangial cell (HMC) at the early stages. Therefore, HMCs cultured in high glucose were used to mimic hyperglycermia. HMC proliferation, cell cycle progression were examined by MTT assay and DNA staining, respectively. Additionally, the role of $\mathrm{NF}-\kappa \mathrm{B}$ was explored by examining its expression as well as its downstream target, MCP-1, which is a putative inflammatory mediator that is upregulated in diabetes and other inflammatory processes 
(17); pyrrolidine dithiocarbamate (PDTC), an inhibitor of $\mathrm{NF}-\kappa \mathrm{B}$ activation, was also employed. These studies may form the basis for the development of potential therapies to treat hyperglycermia-induced DN.

\section{Materials and methods}

Cell culture and treatment. HMCs were kindly provided by Professor Changlin Mei (Department of Nephrology, Shanghai Changzheng Hospital). Cells were cultured in low glucose-containing DMEM medium (Gibco, Carlsbad, CA) supplemented with $10 \%$ fetal calf serum (Jiangbin Biotechnology Co., Ltd., Hangzhou, China), $10^{5} \mathrm{U} / \mathrm{l}$ penicillin (Wuhan Second Pharmaceutical Factory, Wuhan, China), and $10 \mathrm{~g} / \mathrm{l}$ streptomycin (Dalian Pharmaceutical Factory, Dalian, China) at $37^{\circ} \mathrm{C}\left(5 \% \mathrm{CO}_{2}\right)$ in a humidified incubator (Model 2300, Shel-Lab Co., USA). Undert these conditions, the cells maintain with the morpholocial and functional characteristics of normal HMCs. After the cells attained $90 \%$ confluence, they split and counted using $0.25 \%$ trypsin and a Neubauer hemocytometer. Cells were cultured at a density of $1 \times 10^{5} / \mathrm{ml}$ in $25 \mathrm{~cm}^{2}$ culture flasks. After $80 \%$ adherence, the cells were then cultured in low-glucose serum-free DMEM medium for $24 \mathrm{~h}$ for synchronization.

The following treatment groups were used in the present study: i) NG (normal glucose, $5.6 \mathrm{mM}$ ); ii) HG (high glucose, $30 \mathrm{mM}$ ); iii) $\mathrm{HG}+0.1 \%$ DMSO (dimethyl sulfoxide, the National Institute for the Control of Pharmaceutical and Biological Products, China); iv) HG+QU ( quercetin, ranging from $0.5 \times 10^{-5}$ to $\left.\left.4 \times 10^{-5} \mathrm{~mol} / \mathrm{l}\right) ; \mathrm{v}\right) \mathrm{HG}+\mathrm{PDTC}(100 \mu \mathrm{M})$ (Sigma, St. Louis, MO); vi) HG+QU+PDTC. Quercetin was obtained from the National Institute for the Control of Pharmaceutical and Biological Products. Relevant indicators were measured for all the groups at 12, 24 and $48 \mathrm{~h}$ in three independent experiments.

Cell proliferation (MTT) assay. The cells were seeded at a final cell density of $1 \times 10^{4}$ in 96-well plates after which $200 \mu \mathrm{l}$ of $0.4 \%$ calf serum medium was added to each well for $24 \mathrm{~h}$. The cells were synchronized in the stationary phase. Six replication wells for each concentration were used. Cell proliferation was determined by the addition of $20 \mu \mathrm{l}$ of a $5 \mathrm{~g} / \mathrm{l}$ tetrazolium blue (MTT) solution (Fluka Co., USA.) to each well. The cells were incubated at $37^{\circ} \mathrm{C}$ in the dark for $4 \mathrm{~h}$. After the cells were washed, $150 \mu \mathrm{l}$ DMSO was added to each well with agitation for $15 \mathrm{~min}$. After the crystals were fully dissolved, a plate reader (Model 680; Bio-Rad, Hercules, CA) was used to measure the absorbance of each well at $490 \mathrm{~nm}$ with reference at $530 \mathrm{~nm}$. The proliferation and inhibition rates were calculated using the following equations: proliferation rate $=\left(\mathrm{OD}_{\text {high glucose group }}\right.$ $\left.\mathrm{OD}_{\text {normal glucose group }}\right) / \mathrm{OD}_{\text {normal glucose group }} \mathrm{x} 100 / 100$; inhibition rate $=$ $\left(\mathrm{OD}_{\text {high glucose group }}-\mathrm{OD}_{\text {drug group }}\right) / \mathrm{OD}_{\text {high glucose group }} \times 100 / 100$.

Cell cycle analysis. Cells $\left(1 \times 10^{6}\right)$ were collected by centrifugation $(250 \mathrm{x} \mathrm{g}$ for $5 \mathrm{~min}$ ). After the supernatant was removed without disturbing the pellet, $1 \mathrm{ml}$ of ice-cold $70 \% \mathrm{EtOH}$ was added dropwise to the cell pellet with vortexing. Cells were stored at $-20^{\circ} \mathrm{C}$ until DNA staining. One milliliter of DNA staining buffer was added to the pellets for $15 \mathrm{~min}$ before acquisition on the flow cytometer. Data were analyzed by software.
Subcellular fractionation. Cells in log-phase growth were cultured in the following treatment groups: i) NG, ii) HG, iii) HG+PDTC (100 $\mu \mathrm{M}$ PDTC), iv) HG+QU $\left(4 \times 10^{-5} \mathrm{M}\right)$, and v) $\mathrm{HG}+\mathrm{QU}+\mathrm{PDTC}$. Cells were collected at 12, 24 and $48 \mathrm{~h}$ after treatment to observe the nuclear translocation of NF- $\kappa \mathrm{B}$ and MCP-1. Cells were washed with cold PBS, after which $400 \mu 1$ of cold cytoplasmic lysis buffer A (DMSO). The cells were incubated on ice for $30 \mathrm{~min}$. The lysed cells were then scraped, and the cell lysate was transfered to an Eppendorf tube containing $10 \mu \mathrm{l}$ of $10 \% \mathrm{NP}-40$. The tube was strongly agitated in an oscillator for $10 \mathrm{sec}$ at $10,000 \times \mathrm{g}\left(4^{\circ} \mathrm{C}\right)$. The supernatant (i.e., the cytoplasmic fraction) was collected after centrifugation for $5 \mathrm{~min}$ and stored at $-70^{\circ} \mathrm{C}$. To obtain the nuclear fraction, $500 \mu \mathrm{l}$ cold nuclear lysate B was used to resuspend the pellet. After agitation for $30 \mathrm{~min}$ followed by centrifugation for $10 \mathrm{~min}$ at $14,000 \mathrm{x} \mathrm{g}$ at $4^{\circ} \mathrm{C}$, the supernatant (i.e., the nuclear protein extract) was collected and stored at $-70^{\circ} \mathrm{C}$. Protein samples were quantified using a Protein Assay kit (Pierce, Rockford, IL).

Immunocytochemistry. The cells $\left(1 \times 10^{5} / \mathrm{ml}\right)$ were seeded onto sterile slides in 12 -well culture plates for $24 \mathrm{~h}$. After $75 \%$ cells re-attached, the cells were synchronized using serum-free DMEM medium. After $24 \mathrm{~h}$, the culture medium was replaced with DMEM medium containing 5\% serum for another $24 \mathrm{~h}$ culture based on the experimental group requirements after which they were separated into the following treatment groups: i) $\mathrm{NG}$, ii) $\mathrm{HG}$, iii) $\mathrm{HG}+\mathrm{PDTC}(100 \mu \mathrm{M}$ PDTC), iv) $\mathrm{HG}+\mathrm{QU}$ $\left(4 \times 10^{-5} \mathrm{M}\right)$, and v) $\mathrm{HG}+\mathrm{QU}+\mathrm{PDTC}$. At 12,24 and $48 \mathrm{~h}$ after treatment, immunohistochemical analysis was undertaken to observe the nuclear translocation of NF- $\mathrm{kB}$ and MCP-1.

The cells on the coverslips were washed with $0.01 \mathrm{M}$ PBS three times, fixed with $4 \%$ paraformaldehyde for $20 \mathrm{~min}$, and washed again with PBS. The coverslips were then fan-dried at room temperature and mounted with neutral resin. After PBS washing three times for $5 \mathrm{~min}$, the cells were permeabilized with $0.5 \%$ Triton X-100 (Xiamen Tagene Biotechnology Co., Xiamen, China) for $20 \mathrm{~min}$, and washed three times with PBS for $5 \mathrm{~min}$. Endogenous peroxidase was inactivated using 3\% $\mathrm{H}_{2} \mathrm{O}_{2}$ for $15 \mathrm{~min}$. After three more PBS washes for $5 \mathrm{~min}$ each, the cells were incubated in 5\% BSA blocking solution for $15 \mathrm{~min}$ at $37^{\circ} \mathrm{C}$. Cells were next incubated in either mouse anti-human NF-kB (1:100) or rabbit anti-human MCP-1 (1:50) primary antibodies in a humidified chamber overnight at $4^{\circ} \mathrm{C}$. After PBS washing three times for $5 \mathrm{~min}, \mathrm{PV}-9000$ twostep reagents (Zhongshan Goldenbridge Biotechnology Co., Ltd., Beijing) 1 and 2 were added dropwise sequentially and incubated for 20 and $30 \mathrm{~min}$ at $37^{\circ} \mathrm{C}$, respectively. After PBS washing three times for $5 \mathrm{~min}, \mathrm{DAB}$ developing was performed using DAB development kit (Zhongshan Goldenbridge Biotechnology Co., Ltd.), according to the manufacturer's instructions. The slides were rinsed thoroughly with distilled water prior to hematoxylin staining for 15-30 sec and gradient alcohol dehydration. The slides were mounted and observed under a microscope (Nikon AFS-DX, Japan).

Cells containing yellow-brown particles in more than 25\% of the cytoplasm and nucleus were defined as positive. The densest areas of positive NF- $\mathrm{kB}$ p 65 and MCP-1 cells were selected separately for counting under x200 magnification; four areas of each treatment in triplicate were analyzed. ImagePlus 5.0 software was used to analyze the ratio of positive cells. 
A Gross examination of HMC under normal (NG) or high glucose (HG) condition

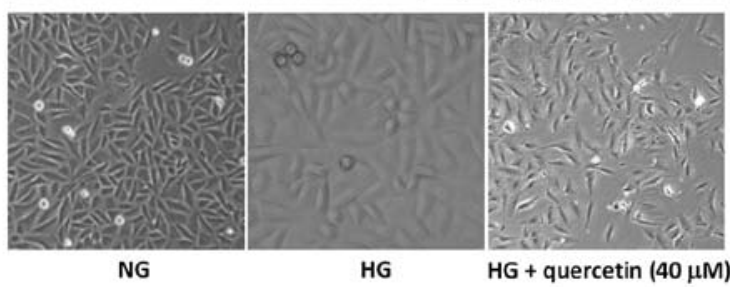

B Cell proliferation in normal or high glucose medium

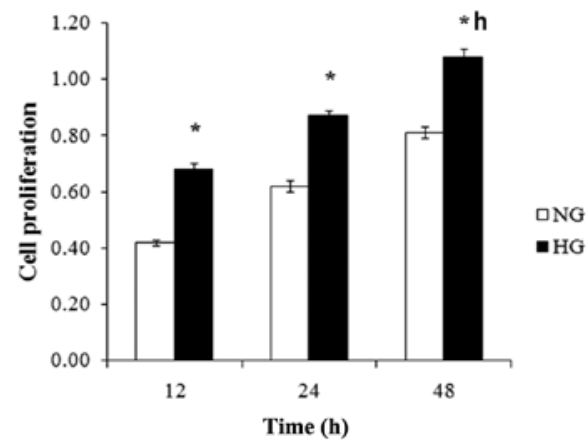

C Dose-dependent inhibition by quercetin on high glucoseinduced HMC proliferation

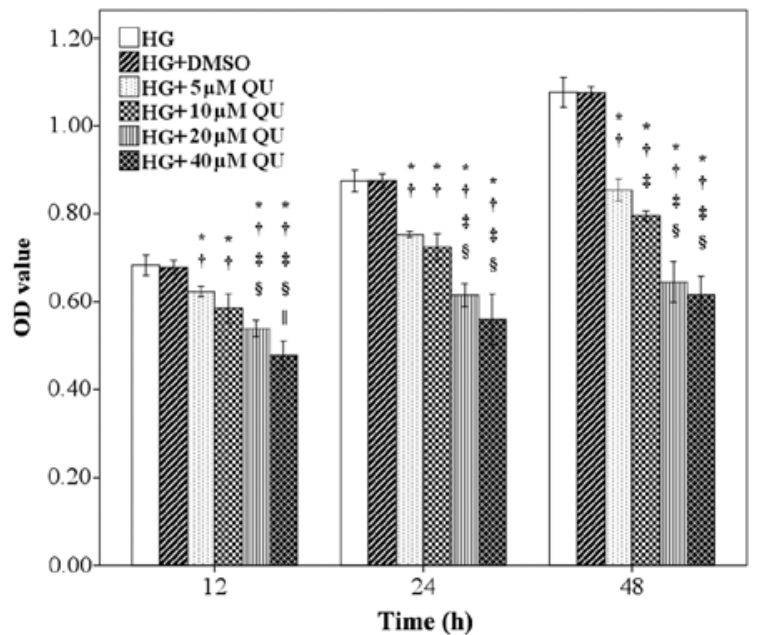

Figure 1. High glucose-cultured HMCs were used as an in vitro DN model. (A) Phase contrast microscopy of HMCs cultured in normal glucose (NG) high glucose (HG) or $\mathrm{HG}+$ quercetin $(40 \mu \mathrm{M})$ for $48 \mathrm{~h}$. (B) Cell proliferation was determined at the indicated time point. ${ }^{*} \mathrm{P}<0.05$, represents a significan difference between NG and HG. (C) Dose-dependent inhibition by quercetin on high glucose-induced HMC proliferation.There are 6 samples in each group at each time point. ${ }^{*} \mathrm{P}<0.05$ compared with $\mathrm{HG}$; ${ }^{\mathrm{P}} \mathrm{P}<0.05$ compared with HG+DMSO; ${ }^{+} \mathrm{P}<0.05$ compared with $\mathrm{HG}+5 \mu \mathrm{M}$ QU; ${ }^{\circledR} \mathrm{P}<0.05$ compared with $\mathrm{HG}+10 \mu \mathrm{M}$ QU; "P $<0.05$ compared with $\mathrm{HG}+20 \mu \mathrm{M}$ QU.

Western blot analysis. Cells were cultured in $25 \mathrm{~cm}^{2}$ flasks and underwent the following treatments: i) $\mathrm{NG}$, ii) $\mathrm{HG}$, iii) HG+PDTC (100 $\mu \mathrm{M}$ PDTC), iv) HG+QU $\left(4 \times 10^{-5} \mathrm{M}\right)$, and v) HG+QU+PDTC. All cells were collected in logarithmic phase growth. After washing with cold PBS, $400 \mu 1$ cold lysis buffer A was added for 30 min with occasional mixing. Cells were harvested by scraping, and lysates were obtained by centrifugation at $10,000 \mathrm{x} \mathrm{g}$ for $5 \mathrm{~min}$ at $4^{\circ} \mathrm{C}$. Supernatants were collected and stored at $-70^{\circ} \mathrm{C}$ until use. Protein concentrations were analysed using the Protein Assay kit (Pierce) following the manufacturer's instructions. Samples $(25 \mathrm{ml})$ were separated on $10 \%$ SDS-PAGE followed by electrotransferred to PVDF membrane (Pierce) as per the manufacturer's instructions. The PVDF membraneswere incubated for $2-4 \mathrm{~h}$ at room temperature or at $37^{\circ} \mathrm{C}$ after the addition of $0.1 \mathrm{ml} /$ $\mathrm{cm}^{2}$ blocking solution containing $10 \%$ skim milk powder (Boster Bioengineering Co., Ltd., Wuhan, China) and 0.05\% Tween-20 (Sigma) TBST. The membranes were incubated overnight at $4^{\circ} \mathrm{C}$ with the following primary antibodies diluted in the blocking solution containing 5\% skim milk powder and 0.05\% TBST: NF-кB p65 (1:400; Santa Cruz Biotechnology, Inc., Santa Cruz, CA), MCP-1 (1:200; Boster Bioengineering Co.), and $\beta$-actin (1:500; Santa Cruz Biotechnology, Inc.). After the membranes were rinsed with TBS containing $0.05 \%$ Tween-20 three times for $10 \mathrm{~min}$, they were incubated with the appropriate secondary antibody (HRP-conjugated goat anti-rabbit and goat anti-mouse antibodies; Santa Cruz Biotechnology, Inc.) diluted in the blocking solution at 1:5,000 for $2 \mathrm{~h}$ at room temperature. The membranes were collected and rinsed with TBS containing $0.05 \%$ Tween-20 three times for $10 \mathrm{~min}$ after which they were incubated with an enhanced chemiluminescence reagent (Zhongshan Goldenbridge Biotechnology Co., Ltd.) and exposed to X-OMAT BT medical X-ray film (Kodak). The bands were analyzed using Quantity One software. NF- $\mathrm{kB}$ p65 or MCP-1 protein expression was normalized to the housekeeping gene, $\beta$-actin.

Statistical analysis. The results were expressed as means and standard deviations (SDs). The comparison of means among the six treatment groups was performed by one way analysis of variance (ANOVA). When a significant difference was found, multiple comparisons were conducted by the Bonfferoni procedure with type-I error adjustment. The level of significance was set at 0.05 . Statistical analyses were performed using SAS 9.1 statistical software (SAS Institute Inc., Cary, NC).

\section{Results}

High glucose-cultured HMCs successfully represents an in vitro DN model. High glucose-cultured HMCs were used to mimic hyperglycermia in this study since hyperproliferation of HMCs was featured at the early stages of DN. Gross morphorlogy examination revealed that HMCs cultured in normal glucose (NG) media were spindleshaped, irregular star-shaped, or triangular, with mostly oval, dark nuclei, and numerous short or long cytoplasmic protrusions (Fig. 1A). Upon culturing in high glucose (HG) medium, the cells became hypertrophic and had altered morphology.

To ensure the high glucose $(30 \mathrm{mM})$ condition in HMCs appropriately represent an in vitro DN model, cell proliferation was examined by MTT assay. Cell proliferation significantly increased in high glucose-tcultured HMCs as compared to the cells cultured with normal glucose $(5.6 \mathrm{mM})$ at 12,24 and $48 \mathrm{~h}(\mathrm{P}<0.001)$ (Fig. 1B). The cell proliferation in the HG group increased by $62.04,41.63$ and $32.66 \%$ at 12,24 and $48 \mathrm{~h}$, respectively. These data indicate that high glucose-cultured HMCs mimic the physiology observed in DN with the characteristics of HMC hyperproliferation. 


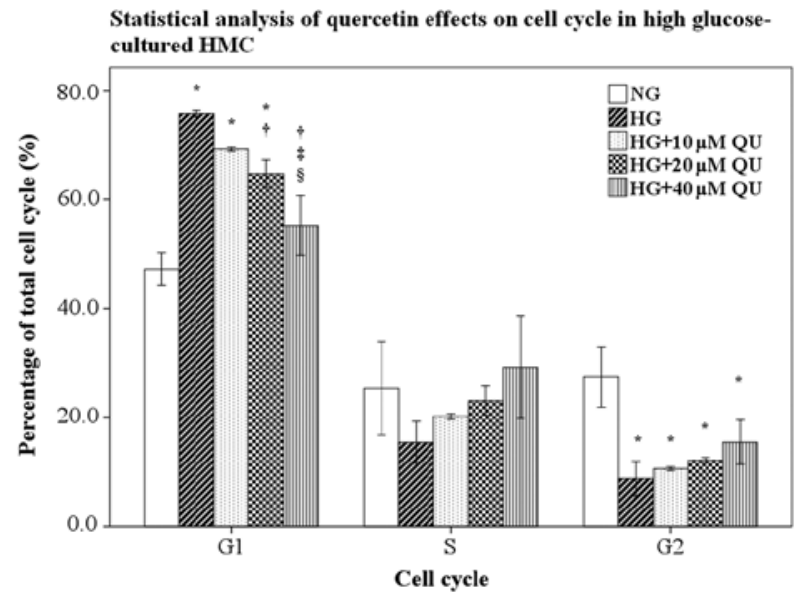

Figure 2. Effects of high glucose and quercetin on cell cycle progression. HMCs were treated with the indicated concentration of quercetin for $48 \mathrm{~h}$ after which the effects on cell cycle in high glucose-cultured HMCs were determined. Data are expressed as means and SDs. The experiments were repeated 3 times. ${ }^{*} \mathrm{P}<0.05$ compared with $\mathrm{NG}$; ${ }^{ } \mathrm{P}<0.05$ compared with $\mathrm{HG}$; ${ }^{\circ} \mathrm{P}<0.05$ compared with $\mathrm{HG}+10 \mu \mathrm{M} \mathrm{QU} ;{ }^{\S} \mathrm{P}<0.05$ compared with $\mathrm{HG}+20 \mu \mathrm{M}$ QU.

A Spatial and temporal expression NF-KB upon high glucose stimulation

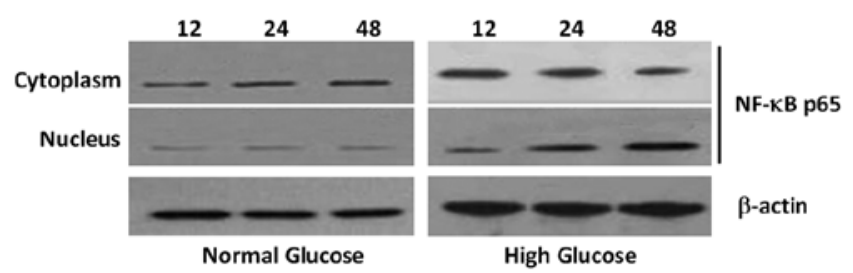

B Temporal expression MCP-1 upon high glucose stimulation

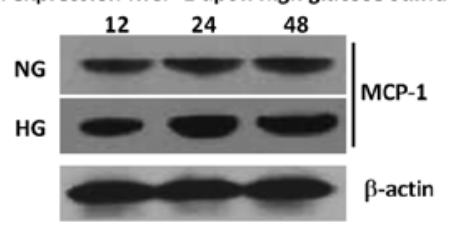

Figure 3. High glucose-induced spatial and temporal expression of NF-kB and MCP-2. NF- $\mathrm{KB}$ and MCP-1 protein expression upon high glucose stimulation was determined using western blot analysis. $\beta$-actin was served as the loading control. (A) Spatial and temporal expression of NF- $\mathrm{\kappa B}$ upon high glucose stimulation for 12, 24 and $48 \mathrm{~h}$. (B) Temporal expression of MCP-1 upon high glucose stimulation for 12, 24 and $48 \mathrm{~h}$.

Effects of quercetin on morphology and proliferation in high glucose-cultured HMCs. Protective effects of quercetin in diabetes mellitus and DN have also been reported in rat models (12-14). Our data showed that quercetin treatment at $40 \mu \mathrm{M}$ led to smaller cells with irregular shapes, larger gaps between adjacent cells, and weakened cell adhesion (Fig. 1A). To examine the influence of quercetin on HG-induced HMC hyperproliferation, quercetin of various concentrations were added to the HMC cultures in the presence of high glucose. There was no difference in cell proliferation between the $\mathrm{HG}$ alone and vehicle control groups (HG+DMSO) at 12, 24 and $48 \mathrm{~h}$ (Fig. 1C). However, quercetin exhibited a significant inhibitory effect on HG-induced HMC proliferation at 12, 24 and $48 \mathrm{~h}$ in a dose-dependent manner (all $\mathrm{P}<0.001$ ).
A Quercetin and PDTC down-regulate high glucose-induced NF-KB and MCP-1 expression

\begin{tabular}{c|c|c|c|c|c}
\hline PDTC & $\cdot$ & $\cdot$ & $\cdot$ & + & + \\
\hline quercetin & $\cdot$ & $\cdot$ & + & $\cdot$ & + \\
\hline Glucose & normal & \multicolumn{3}{|c}{ high } \\
NF-KB p65 & $-\infty$ \\
$\beta$-actin & \\
MCP-1 & \\
$\beta$-actin
\end{tabular}

B Statistical analysis of quercetin and PDTC effects on high glucoseinduced NF-kB and MCP-1 expression

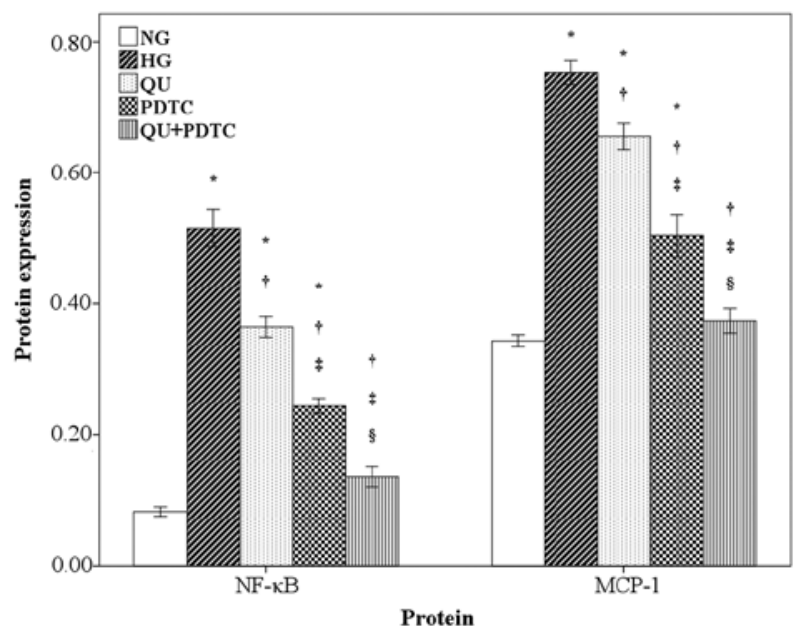

Figure 4. Effects of quercetin on HG-induced NF- $\mathrm{KB}$ and MCP-2 protein expression. NF- $\mathrm{KB}$ and $\mathrm{MCP}-1$ protein expression was determined using western blot analysis. $\beta$-actin was served as the loading control. (A) Reprentative image of NF- $\mathrm{kB}$ and MCP-1 protein expression. (B) Data are represented as means and SDs. There are 6 samples in each group. ${ }^{*} \mathrm{P}<0.05$ compared with NG group; ${ }^{\dagger} \mathrm{P}<0.05$ compared with $\mathrm{HG} ;{ }^{*} \mathrm{P}<0.05$ compared with QU; ${ }^{\circledR} \mathrm{P}<0.05$ compared with PDTC.

Effects of high glucose and quercetin on cell cycle progression. Since quercetin exerted an inhibitory effect on high glucoseinduced HMC proliferation, we next examined whether quercetin affects cell cycle progression that results in decreased cell proliferation. High glucose significantly increased the percentage of cells in G1 phase $(75.73 \pm 0.59 \%)$ as compared to the NG group $(\mathrm{P}<0.05)$ (Fig. 2). High glucose-cultured HMC presented a dose-dependent decrease in percentages of G1 cells in response to quercetin treatment. HMC cultured in high glucose exhibited a significant decrease in the percentage of G2

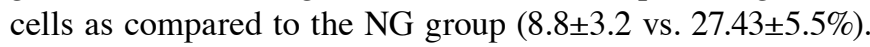
Treatment of quercetin at various concentrations in HG-cultured HMCs showed a trend towards increasing the percentages of G2 cells, however, no significant difference was observed.

High glucose-induced spatial and temporal expression of $N F-\kappa B$ and $M C P-2$. It has been reported that dietary quercetin attenuated fasting and postprandial hyperglycemia (15) and quercetin was proven to block NF- $\mathrm{kB}$ signaling in a portal hypertensive rat model (16). The expression patterns of NF- $\mathrm{KB}$ and its known downstream inflammatory factor MCP-1 were thus determined in the absence or presence of high glucose. It 
A

Quercetin and PDTC effects on NF-KB and MCP-2 expression visualized by ICC in high glucose-cultured HMCs

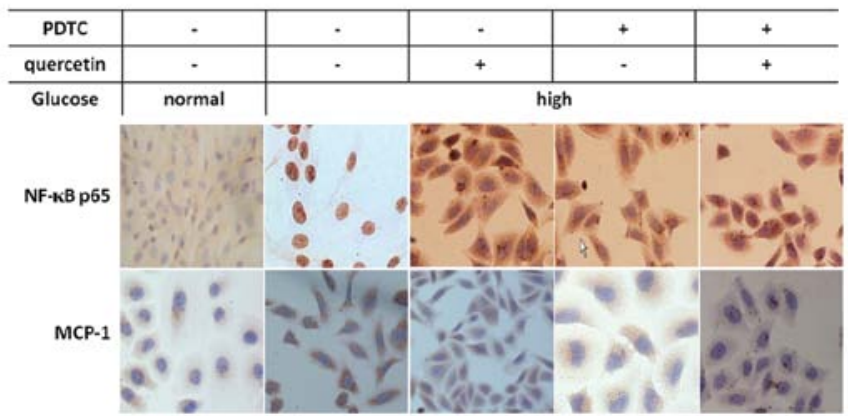

B

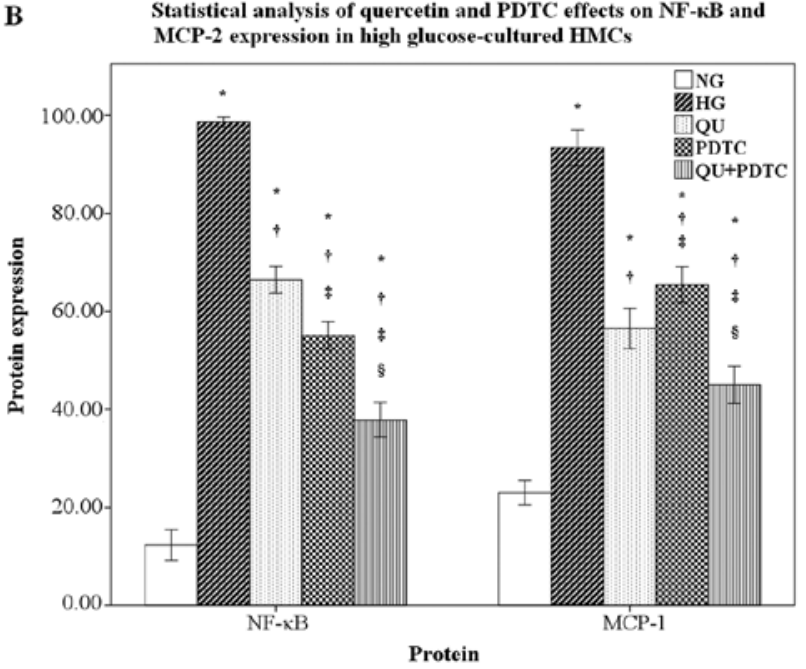

Figure 5. Effects of quercetin on HG-induced NF- $\kappa$ B and MCP-2 protein expression were visualized by ICC. (A) Representative images of each treatment group are shown. (B) Data are represented as means and SDs. There are 6 samples in each group. ${ }^{*} \mathrm{P}<0.05$ compared with negative control group; ${ }^{\dagger} \mathrm{P}<0.05$ compared with $\mathrm{HG} ;{ }^{*} \mathrm{P}<0.05$ compared with $\mathrm{QU} ;{ }^{\circledR} \mathrm{P}<0.05$ compared with PDTC.

is well known that activated NF- $\mathrm{B}$ translocates from the cytoplasm into the nucleus. We examined the spatial and temporal expression of NF- $\mathrm{NB}$ in HMC cultured under NG or HG conditions. The HMC under high glucose condition exhibited not only increased protein levels of $\mathrm{NF}-\kappa \mathrm{B}$ but also altered distribution, $\mathrm{NF}-\kappa \mathrm{B}$ translocated from the cytoplasm to nucleus (Fig. 3A). Expression of MCP-1, one of the prominent downstream factors in $\mathrm{NF}-\kappa \mathrm{B}$ signaling, was simultaneously examined and the data showed that MCP-1 expression was increased in response to $\mathrm{HG}$ stimulation at indicated time periods (Fig. 3B).

Effects of quercetin on $H G$-induced $N F-\kappa B$ and $M C P-2$ protein expression. The effect of quercetin on $\mathrm{HG}$-induced $\mathrm{NF}-\kappa \mathrm{B}$ activity in HMC was examined. Fig. 4A shows a representative image of western blotting. HMCs cultured under NG condition exhibited basal levels of NF- $\kappa \mathrm{B}$ and MCP-1 expressions, while high glucose condition significantly increased $\mathrm{NF}-\kappa \mathrm{B}$ and MCP-1 expression ( $\mathrm{P}<0.05)$ (Fig. 4). Quercetin treatment, which has an inhibitory effect on $\mathrm{HG}$-induced HMC proliferation, was observed to suppress both $\mathrm{NF}-\kappa \mathrm{B}$ and $\mathrm{MCP}-1$ expression significantly as compared to the HG group $(\mathrm{P}<0.01)$. PDTC, a putative inhibitor of NF- $\kappa \mathrm{B}$ activity, was introduced and acted as expected to inhibit NF- $\kappa \mathrm{B}$ activation induced by $\mathrm{HG}$ condition. Either quercetin or PDTC suppressed HG-induced NF- $\mathrm{BB}$ and MCP-1 expression; however, both contributed partially to the suppression of expression. Combined treatment of quercetin and PDTC exhibited additive effect on inhibition of $\mathrm{NF}-\kappa \mathrm{B}$ and MCP-1 expression, which was significantly lower than either treatment alone $(\mathrm{P}<0.01)$ and almost at the basal level as compared to the NG group.

The effects of high glucose and quercetin on $N F-\kappa B$ and MCP-1 expression were further confirmed using immunocytochemistry (Fig. 5). Representative images are shown in Fig. 5A for all treatment groups. The basal level expression of $\mathrm{NF}-\kappa \mathrm{B}$ and MCP-1 was observed in the NG group and was significantly increased upon culturing in $\mathrm{HG}$ condition $(\mathrm{P}<0.05)$. The expression of NF- $\kappa \mathrm{B}$ and MCP-1 significantly decreased in the quercetin and PDTC groups. Cotreatment with QU+PDTC further reduced the expression of both NF- $\kappa \mathrm{B}$ and MCP-1 $(\mathrm{P}<0.001)$.

\section{Discussion}

Because a role for inflammation in the pathogenesis of DN has increasingly been observed (18), it has been suggested that quercetin's anti-inflammatory properties may mediate its protective effects against DN. The objective of this study was to identify the underlying mechanism for quercetin protection against DN. HMCs cultured in high glucose had significantly greater proliferation, accumulation in the G1 phase, upregulated $\mathrm{NF}-\kappa \mathrm{B}$ and $\mathrm{MCP}-1$ expression. These effects were reversed with quercetin treatment in a dose-dependent manner.

Culturing HMCs in high glucose was used as a model to mimic their proliferation observed in the early stages of DN and resulting pathological cause of renal dysfunction. In the present study, increased HMC proliferation was observed upon culturing in high glucose-containing medium, which is consistent with the results from previous studies $(18,19)$. Additionally, increased MC proliferation with high glucose treatement associated with decreased p21 and increased CDK4 and CDK2 activity (19), which was reflected in the present study as hyperproliferation of HMCs and an increased percentage of HMCs in G1 phase were observed upon culture in high glucose condition.

Studies have shown that high in vitro glucose serves a dual function on HMC growth, stimulating proliferation within $48 \mathrm{~h}$ while suppressing it after $72 \mathrm{~h}(20,21)$. However, the exact mechanism governing these effects remains to be determined. Chronic exposure of HMCs to HG may induce apoptotic signaling, possibly resulting in microvascular injury to the diabetic kidney (22). Because we wanted to determine the effects of quercetin on DN, characterized by HMC hyperproliferation, all studies were assessed at $48 \mathrm{~h}$ culture in high glucose-containing medium.

Quercetin significantly inhibited the proliferation of high glucose-induced HMCs in a dose-dependent manner. Because of QU's anti-inflammatory functions, its effects on $\mathrm{NF}-\kappa \mathrm{B}$ expression, a transcription factor that regulates the expression of cytokines, adhesion factors, cytokine receptors, chemokine receptors, and anti-apoptotic proteins (23), was also assessed. Previous studies have reported that high glucose can activate $\mathrm{NF}-\kappa \mathrm{B}$ in $\mathrm{HMCs}$ through protein kinase $\mathrm{C}$ (PKC) and reactive oxygen species (ROS) signaling, stimulating proliferation of HMCs and the secretion of 
inflammatory mediators, such as MCP-1. In the present study, high glucose treatment induced expression of $\mathrm{NF}-\kappa \mathrm{B}$ as well as its downstream target, MCP-1, which is similar to that reported in previous studies $(24,25)$. In addition, quercetin decreased both NF- $\mathrm{NB}$ and MCP-1 expression, which was similar to that observed in mast cells and endothelial cell, respectively $(26,27)$. Furthermore, additive effects of cotreatment with quercetin and PDTC, an inhibitor of NF- $\kappa \mathrm{B}$ activity, were observed.

MCP-1 induces macrophage infiltration in kidney tissues, clears glycosylated albumin and oxidized-LDL, and reduces renal tissue damage (28); its expression increases in the renal tissues of DN patients. Its local overexpression could prolong the inflammatory state, inducing renal tissue damage (29). High blood glucose may induce MCP-1 expression through the p38 MAPK signaling in endothelial cells and glomerular MCs; it also directly stimulates MCP-1 mRNA and protein expression in glomerular MCs (30). In type 2 DM patients, plasma MCP-1 expression was significantly higher than that in healthy volunteers, and it was also positively correlated to urinary albumin excretion (31). Chacón et al (32) reported increased MCP-1 mRNA expression in the adipose tissues of patients with type $2 \mathrm{DM}$.

In the present study, PDTC was used as a specific inhibitor as control to compare with the effectiveness of quercetin. It is a specific NF- $\kappa \mathrm{B}$ inhibitor that prevents IKB phosphorylation, reducing IKB degradation as well as decreasing lipid peroxidase activity recent studies have confirmed that PDTC can induce tumor cell apoptosis.

Quercetin and its derivatives are the most widely distributed flavonoids in the plant kingdom without obvious side effects. They have many pharmacological activities, mainly including anti-oxidant, anti-inflammatory, free radical scavenging, blood pressure lowering, anti-canceration, anti-aging, anti-mutagenic, and anti-atherosclerosis effects $(16,17)$. However, whether quercetin can inhibit NF- $\kappa \mathrm{B}$ signaling has yet to be determined. Recent studies have shown that ROS, as an important stimulator of NF- $\kappa \mathrm{B}$ activation, and plays a key role in DN pathogenesis (6). Therefore, we speculated that the protective effects of quercetin may be a result of blocking the ROS-NF- $\kappa \mathrm{B}$ inflammatory pathway. In the present study, quercetin inhibited the expression of $\mathrm{NF}-\kappa \mathrm{B}$ and $\mathrm{MCP}-1$ in $\mathrm{HMCs}$, suggesting that its anti-inflammatory function may block the development of diabetic glomerular inflammation. Although this provides a theoretical basis to further understand and evaluate the role of quercetin in the prevention and treatment of diabetic nephropathy, further in vivo studies are necessary.

The present study has limitations that warrent discussion. Firstly, the effects of quercetin were only analyzed using in vitro studies. Therefore, analysis of the effects of quercetin in an animal model of DN is required. Furthermore, although these results showed that quercetin has, to some extent, an inhibitory effect on the NF- $\mathrm{BB}$ signaling pathway, the mechanism by which it inhibits $\mathrm{NF}-\kappa \mathrm{B}$ activation and the specific functions of its target genes in DN requires further investigation. In addition, its effects on ROS were not explored.

In conclusion, in summary, high glucose stimulates $\mathrm{HMC}$ proliferation as well as the expression of $\mathrm{NF}-\kappa \mathrm{B}$ p65 and MCP-1, which may further induce structural damage of glomerular MCs and thereby alter kidney function. Quercetin reduces HMC proliferation in response to high glucose and reduces $\mathrm{NF}-\kappa \mathrm{B}$ p65 and $\mathrm{MCP}-1$ expression. Thus, its antiinflammatory activity may be responsible for its protective effects observed in diabetic kidneys.

\section{Acknowledgements}

We thank Dr Changlin Mei, Shanghai Changzheng Hospital, Professor of Renal Medicine, for providing epithelial human mesangial cells. Funding by the Natural Science Foundation of Fujian Province (2008J0104).

\section{References}

1. Xiangjin $X$ and Jiaqing $Z$ : Inhibition of quercetin on nonenzymatic glycation and oxidation of diabetic rat kidneys. J Endocrinol Metabol 14: 34-37, 1998 (In Chinese).

2. Ruoslahti E, Yamaguchi Y, Hildebrand A and Border WA: Extracellular matrix/growth factor interactions. Cold Spring Harb Symp Quant Biol 57: 309-315, 1992.

3. Kamanna VS, Bassa BV and Ganji SH: Low density lipoproteins transactivate EGF receptor: role in mesangial cell proliferation. Life Sci 83: 595-601, 2008.

4. Flavonoids: Chemistry, Biochemistry and Applications. Andersen OM, Markham KR (eds). CRC Press, Boca Raton, pp1-1256, 2006.

5. Walker EH, Pacold ME, Perisic O, Stephens L, Hawkins PT, Wymann MP and Williams RL: Structural determinants of phosphoinositide 3-kinase inhibition by wortmannin, LY294002, quercetin, myricetin, and staurosporine. Mol Cell 6: 909-919, 2000.

6. Engelman JA, Luo J and Cantley LC: The evolution of phosphatidylinositol 3-kinases as regulators of growth and metabolism. Nat Rev Genet 7: 606-619, 2006.

7. Foukas LC and Withers DJ: Phosphoinositide signalling pathways in metabolic regulation. Curr Top Microbiol Immunol 346: 115-141, 2010.

8. Cho SY, Park SJ, Kwon MJ, et al: Quercetin suppresses proinflammatory cytokines production through MAP kinases and NF-kappaB pathway in lipopolysaccharide-stimulated macrophage. Mol Cell Biochem 243: 153-160, 2003.

9. Amalia PM, Possa MN, Augusto MC and Francisca LS: Quercetin prevents oxidative stress in cirrhotic rats. Dig Dis Sci 52: 2616-2621, 2007.

10. Hartge MM, Unger T and Kintscher U: The endothelium and vascular inflammation in diabetes. Diab Vasc Dis Res 4: 84-88, 2007.

11. Coskun O, Kanter M, Korkmaz A and Oter S: Quercetin, a flavonoid antioxidant, prevents and protects streptozotocin-induced oxidative stress and $\beta$-cell damage in rat pancreas. Pharmacol Res 51: 117-123, 2005.

12. Shetty AK, Rashmi R, Rajan MGR, Sambaiah K and Salimath PV: Antidiabetic influence of quercetin in streptozotocin-induced diabetic rats. Nutr Res 24: 373-381, 2004.

13. Ramachandra R, Shetty AK and Salimath PV: Quercetin alleviates activities of intestinal and renal disaccharidases in streptozotocininduced diabetic rats. Mol Nutr Food Res 49: 355-360, 2005.

14. Anjaneyulu M and Chopra K: Quercetin, an anti-oxidant bioflavonoid, attenuates diabetic nephropathy in rats. Clin Exp Pharmacol Physiol 31: 244-248, 2004

15. Kim JH, Kang MJ, Choi HN, Jeong SM, Lee YM and Kim JL: Quercetin attenuates fasting and postprandial hyperglycemia in animal models of diabetes mellitus. Nutr Res Pract 5: 107-111, 2011.

16. Moreira AJ, Fraga C, Alonso M, et al: Quercetin prevents oxidative stress and NF-kappaB activation in gastric mucosa of portal hypertensive rats. Biochem Pharmacol 68: 19391946, 2004.

17. Ha $\mathrm{H}$ and Lee HB: Reactive oxygen species amplify glucose signalling in renal cells cultured under high glucose and in diabetic kidney. Nephrology 10: S7-S10, 2005.

18. Yuan P, Xue H, Zhou L, et al: Rescue of mesangial cells from high glucose-induced over-proliferation and extracellular matrix secretion by hydrogen sulfide. Nephrol Dial Transplant 26: 2119-2126, 2011. 
19. Danesh FR, Sadeghi MM, Amro N, et al: 3-Hydroxy3-methylglutaryl CoA reductase inhibitors prevent high glucose-induced proliferation of mesangial cells via modulation of Rho GTPase/p21 signaling pathway: implications for diabetic nephropathy. Proc Natl Acad Sci USA 99: 8301-8305, 2002.

20. Gruden G, Perin PC and Camussi G: Insight on the pathogenesis of diabetic nephropathy from the study of podocyte and mesangial cell biology. Curr Diabetes Rev 1: 27-40, 2005.

21. Sodhi CP, Phadke SA, Batlle D and Sahai A: Hypoxia and high glucose cause exaggerated mesangial cell growth and collagen synthesis: role of osteopontin. Am J Physiol Renal Physiol 280: F667-F674, 2001.

22. Mishra R, Emancipator SN, Kern T and Simonson MS: High glucose evokes an intrinsic proapoptotic signaling pathway in mesangial cells. Kidney Int 67: 82-93, 2005.

23. Karin M and Ben-Neriah Y: Phosphorylation meets ubiquitination: the control of NF-(kappa)B activity. Annu Rev Immunol 18: 621-663, 2000.

24. Ha H, Cha MK, Choi HN and Lee HB: Effects of peritoneal dialysis solutions on the secretion of growth factors and extracellular matrix proteins by human peritoneal mesothelial cells. Perit Dial Int 22: 171-177, 2002.

25. Ihm CG, Park JK, Hong SP, et al: A high glucose concentration stimulates the expression of monocyte chemotactic peptide 1 in human mesangial cells. Nephron 79: 33-37, 1998.

26. Min YD, Choi CH, Bark H, et al: Quercetin inhibits expression of infl ammatory cytokines through attenuation of NF-kappaB and p38 MAPK in HMC-1 human mast cell line. Inflamm Res 56: 210-215, 2007.
27. Retnamma Panickera S, Sreenivasb P, Sankar Babuc M, Karunagarand D and Cheranellore Kartha C: Quercetin attenuates monocyte chemoattractant protein-1 gene expression in glucose primed aortic endothelial cells through NF-kappaB and AP-1. Pharmacol Res 62: 328-336, 2010.

28. Basta G, Schmidt AM and De Caterina R: Advanced glycation end products and vascular inflammation: implications for accelerated atherosclerosis in diabetes. Cardiovasc Res 63: 582-592, 2004.

29. Kiyici S, Erturk E, Budak F, et al: Serum monocyte chemoattractant protein-1 and monocyte adhesion molecules in type 1 diabetic patients with nephropathy. Arch Med Res 37: 998-1003, 2006.

30. Banba N, Nakamura T, Matsumura M, Kuroda H, Hattori Y and Kasai K: Possible relationship of monocyte chemoattractant protein-1 with diabetic nephropathy. Kidney Int 58: 684-690, 2000.

31. Tashiro K, Koyanagi I, Saitoh A, et al: Urinary levels of monocyte chemoattractant protein-1 (MCP-1) and interleukin-8 (IL-8), and renal injuries in patients with type 2 diabetic nephropathy. J Clin Lab Anal 16: 1-4, 2002.

32. Chacón MR, Fernández-Real JM, Richart C, et al: Monocyte chemoattractant protein-1 in obesity and type 2 diabetes. Insulin sensitivity study. Obesity (Silver Spring) 15: 664-672, 2007. 